\title{
Evaluating containment operational reliability of nuclear power plant units with the VVER-1000 reactor in operation
}

\author{
Yuri Pimshin ${ }^{1, *}$, Yuri Zayarov ${ }^{1}$, Yuri Zabaznov ${ }^{1}$, and Galina Naumenko ${ }^{2}$ \\ ${ }^{1}$ Volgodonsk Engineering Technical Institute the branch of National Research Nuclear University \\ "MEPhI", 73/94, Lenina str., Volgodonsk, 347360, Russia \\ ${ }^{2}$ Don State Technical University (DSTU), 1, Gagarin square, Rostov-on-Don, 344000, Russia
}

\begin{abstract}
The theory of the containment technical condition estimation of NPP units is considered in the paper. The theory is that the results of a regular built-in system intended for determining and evaluation of the containment stress-strain state during the acceptance and operation period must be duplicated by the mobile geodetic system results, obtained at the same stages of the containment existence. At the same time, the proposal for applying this theory to the containments constructed in 1980-2010 has been developed. The possible initial working environment is considered and the proposals for this technique implementation are introduced in the conditions under consideration. The proposals presented provide an objective control of the containment for an unlimited period of their operation.
\end{abstract}

\section{Introduction}

The protective containment is a passive element of the safety system (protection circuits) of NPP units, fig. 1. The main function of the containment is to prevent the radioactive substance releases into the environment during severe accidents and to protect the operating reactor from negative possible external events. Thus, the containment must meet the requirements described above for the entire period of its operation and perform its functions. To ensure safe operation, constant monitoring and evaluation of the technical condition of the containment at all operation stages are carried out. For containment constructed in recent times in accordance with NP-010-16 " Rules for the Design and Operation of Localizing Safety Systems for Nuclear Power Plants" methods for monitoring its technical state have been developed and implemented [1-6]. For containments erected in 1980-2010, the task of assessing the technical state remains relevant, and in some cases this task becomes critical.

\footnotetext{
Corresponding author: YIPimshin@mephi.ru
} 


\section{General methodology for monitoring the containment technical condition}

The proposed and implemented method for monitoring the containment technical condition consists in the fact that the control points are located directly on the surface of the containment, while in the cylindrical part they are placed in the membrane zones on the construction axes of the containment and their position is aligned with the location zones of the sensor blocks of the built-in system, Figure 2. On the dome part of the containment, the controlled points are located on the quarter axes, they are also placed in the membrane zones, and their location is aligned with the sensor block zones of the embedded system. Measuring the locations of the points under study is performed at the following stages: after the complete construction of the containment, after the complete voltage program has been

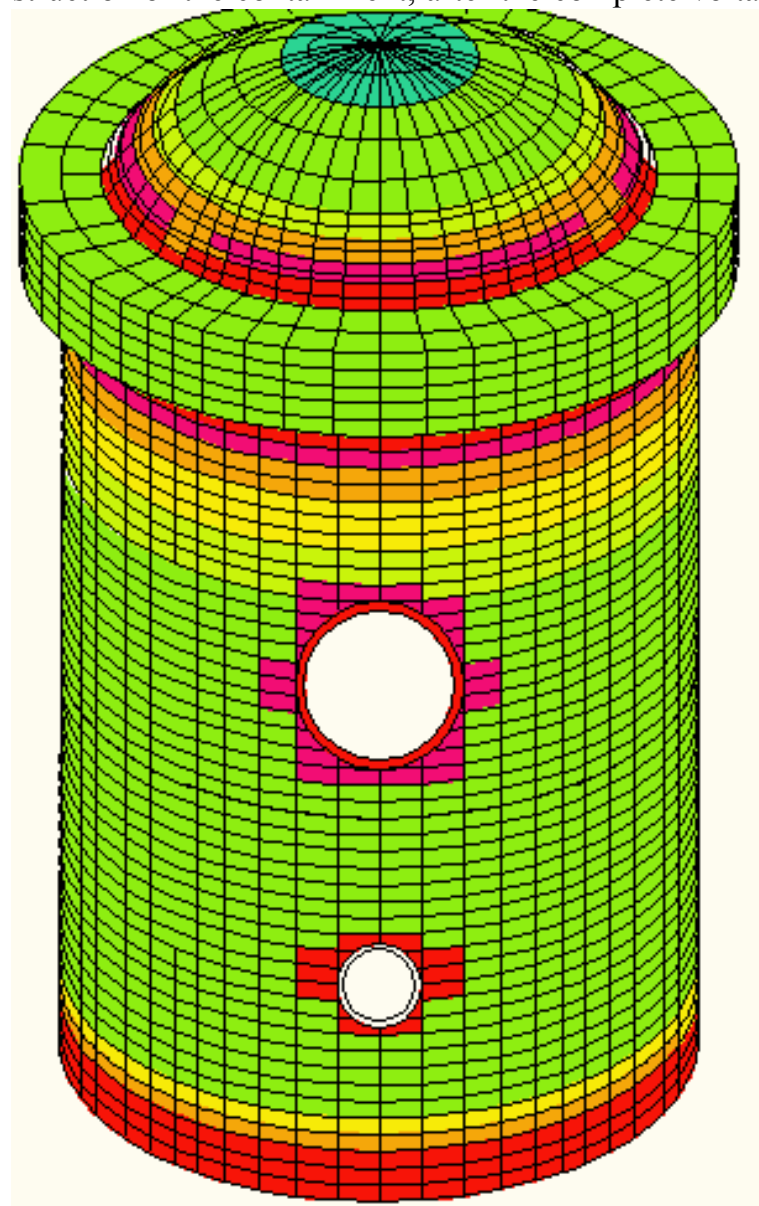

Fig. 1. Containment

performed, during the testing of the containment at the stage of creating the maximum internal pressure and subsequently in operation during the period of each scheduled preventive repair, based on the obtained step-by-step results, the values of the displacements A (i) of the monitored points are determined

$$
\delta_{(i)}=A_{(i)}-A_{(i-1)},
$$


where $A_{(i-1)}, A_{(i)}$ are the measured parameters of the investigated points at the previous $(i-1)$ and subsequent $(i)$ stages;

$\delta$ (i) are the corresponding inter-stage parameters of the displacement of the points under study. Then the safety coefficient of the containment building structures is obtained,

$$
\begin{gathered}
K_{0}=\left(\delta_{0} / \delta_{1}\right), \\
K_{(i)}=\left[\delta_{0}+\left(\delta_{2}+\sum_{3}^{n} \delta_{(i)}\right)\right] / \delta_{1},
\end{gathered}
$$

where $K_{0}$ - is the safety coefficient, determined from the results of the pre-stresses $\delta_{0}$ and the containment test $\delta_{1}$;

$K_{(i)}$ - is the safety coefficient, determined from the results of the implementation of $n$ steps at the stage of the containment operation.

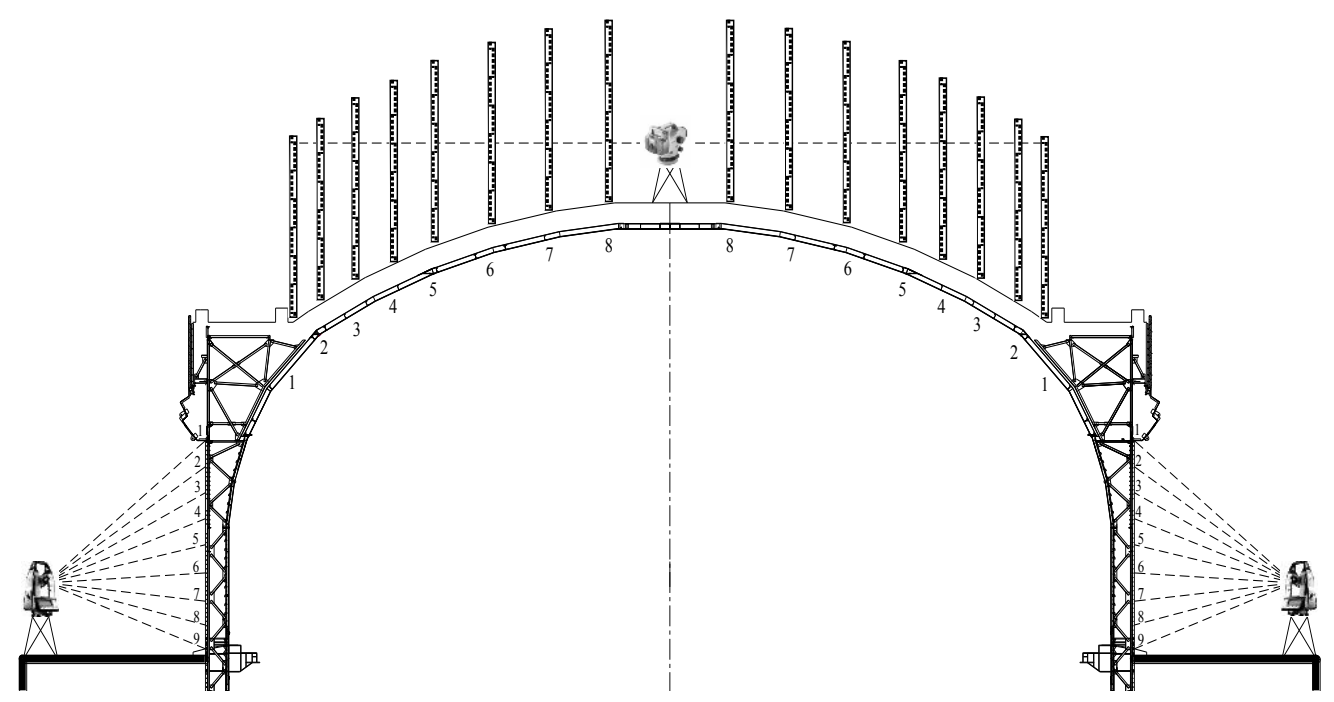

Fig. 2. The location of the control points.

Simultaneously, at the same stages, the voltages are measured by the sensors installed in the circumferential armature, on the cylindrical part, and the circumferential and meridional reinforcement in the dome part, the built-in voltage monitoring system $U_{i}$, by the measured stress values their inter-stage variation is calculated,

$$
\delta_{(i)}^{\prime \prime}=U_{(i)}-U_{(i-1)}
$$

where $U_{(i-1)}, U_{(i)}$ - are the measured voltages for the corresponding sensors of the builtin system at the previous ( $i-1)$ and subsequent ( $i)$ stages;

$\delta_{(i)}^{\prime \prime}$ - are corresponding inter-stage parameters of voltage changes in the placement zones of the corresponding sensors of the built-in system.

In its turn, the safety coefficients $K^{\prime \prime}{ }_{(i)}\left(K^{\prime \prime}{ }_{0}\right)$ are calculated by these factors,

$$
K_{0}^{\prime \prime}=\left(\delta_{0}^{\prime \prime} / \delta_{1}^{\prime \prime}\right)
$$




$$
K_{(i)}^{\prime \prime}=\left[\delta_{0}^{\prime \prime}+\left(\delta_{2}^{\prime \prime}+\sum_{3}^{n} \delta_{(i)}^{\prime \prime}\right)\right] / \delta_{1}^{\prime \prime},
$$

where $K^{\prime \prime}{ }^{\text {- }}$ is the safety coefficient determined from the results of measurements by the built-in system during the realization of pre-stress stages $\delta_{{ }_{0}}$ and the containment test $\delta^{\prime \prime}{ }_{1}$;

$K^{\prime \prime}{ }_{(i)}$ - is the safety coefficient determined by the results of measurements by the built-in system when $n$ steps are implemented at the containment operation stage.

Next, the obtained coefficients are compared

$$
K_{0}-K_{0}^{\prime \prime} \leq \varepsilon \text { or } K_{(i)}-K_{(i)}^{\prime \prime} \leq \varepsilon,
$$

where $\mathcal{E}$ - is a given value of the permissible coefficient differences.

Observance of inequations is a reliable and technical state objective assessment of the containment stressed part. In practice, it is proposed to use the inequation given below

$$
\frac{\left|K_{0}-K_{0}^{\prime \prime}\right|}{K_{0}^{\prime \prime}} \times 100 \% \leq 10 \% \text {. }
$$

\section{The main proposals for monitoring the technical state of the containments erected in $1980-2010$}

Under the preceding inequation (8), the average values of the coefficients are calculated

$$
K_{c p(0)}=\left(K_{0}+K_{0}^{\prime \prime}\right) / 2 \text { or } K_{c p(i)}=\left(K_{(i)}+K_{(i)}^{\prime \prime}\right) / 2 \text {. }
$$

Thus, as a result of monitoring, the safety coefficient $\mathrm{K}_{c p(0)}$ and $K_{c p(i)}$ are determined at the corresponding stages $\mathrm{T}_{(0)}$ and $\mathrm{T}_{(i)}$ of the containment existence. By these results an approximating function of the form is determined

$$
K_{t(i)}=a_{0}+a_{1} \cdot T+a_{2} \cdot T^{2}+a_{3} \cdot T^{3}+a_{4} \cdot T^{4},
$$

and each subsequent value of the calculated coefficient $K_{c p(i)}$ at some instant $\mathrm{T}_{(i)}$ during the containment operation refines the approximating function $K_{t(i)}$.

For containments built and commissioned in 1980-2010, the following conditions for their monitoring are possible.

1. The geodetic control of the surveyed points was carried out while prestressing and testing. And at the subsequent stages of the containment operation these kinds of works were not performed. In this case, for the first stage $K_{c p(0)}$ is calculated by formula (9), for the subsequent stages $K_{c p(i)}$ we take $K_{c p(i)}=K_{(i)}^{\prime \prime}$. Next, the approximating function (10) is determined. Then, using formula (10), $K_{t(n)}$ is calculated at the current time $\mathrm{T}_{(n)}$. Having $\left.\mathrm{K}_{t(n)}\right)$ restore the value|.

$$
\begin{gathered}
\delta_{N}=\left[\delta_{0}+\left(\delta_{2}+\sum_{3}^{n} \delta_{(i)}\right)\right], \\
\delta_{N}=K_{t(n)} \cdot \delta_{1} .
\end{gathered}
$$

For subsequent steps 


$$
K_{t(i)}=\left[\left(\delta_{N}+\sum_{n+1}^{m} \delta_{i}\right) / \delta_{1}\right] .
$$

Thus, the monitoring of the containment current state according to geodetic monitoring data is restored and continues for an unlimited time.

2. The geodetic control at the prestressing and testing stages was not carried out, and later either. In this case, $K_{c p(0)}$, we take $K_{c p(0)}=K^{\prime \prime}(0)$ and $K_{c p(i)}=K^{\prime \prime}{ }_{(i)}$. Next, the approximating function (10) is determined. Then, using formula (10), calculate $K_{t(n)}$ at the current time $\mathrm{T}_{(n)}$. However, in this variant, $\delta_{1}$ was not determined in due time, in accordance with this, $\delta_{1}$ is taken to be the averaged value determined on other similar containments, or calculated from $\delta_{1}{ }_{1}$ as a result of prestressing processes and testing simulation of the given containment. Subsequently, in the same manner as in the first variant, $\delta_{N}$ and $\mathrm{K}_{t(i)}$. are determined. And they also continue to monitor the current state of the containment on an unlimited basis according to the geodetic monitoring data.

We note the following, if at the operation stage, a containment testing is performed, and this is possible with a complete replacement of the pre-stressing system, then the variable $\delta_{1}$ will be determined as a result of on-site measurements at the facility.

\section{Conclusion}

The implementation of the above proposals allows to restore and carry out on an unlimited time interval of operation the objective monitoring of the containment technical state with the WWER-1000 reactor, constructed in the period from 1980 to 2010.

\section{References}

1. Yu.I. Pimshin, E.B. Klyushin, V.N.Medvedev, O.A.Gubeladze, V.A.Naugolnov, Yu.V. Zayarov, Yu.S. Zabaznov, Izv.vuz. «Geod. and aeroph.», 4, 55 (2016)

2. Yu.I. Pimshin, V.N.Medvedev, G.A.Naumenko, V.A.Naugolnov, Yu.S. Zabaznov, Izv.vuz. «Geod. and aeroph.», 3, 36 (2017)

3. Yu.I.Pimshin, V.A.Naugolnov, I.Yu.Pimshin, Yu.S.Zabaznov, V.V.Yakovlev, RF Patent No 2426 089, Byull. Izobret., No. 22 (2011)

4. Yu.I.Pimshin, Yu.S.Zabaznov, O.A. Gubeladze, P.Yu.Pimshin, Patent RF No 2546 990, Byull. Izobret., No. 10 (2015)

5. Yu. I.Pimshin, E.B Klyushin, Yu. S.Zabaznov, O.A Gubeladze, P. Yu.Pimshin, Patent RF No 2577 555, Byull. Izobret., No. 8 (2016)

6. Federal Norms and Rules for the Atomic Energy Use NP-010-16 (2016) 